\title{
Carbohydrate Affinity PAGE for the Study of Carbohydrate-Binding Proteins
}

BioTechniques 25:146-151 (July 1998)

\author{
Phil D. Rye and Nicolai V. \\ Bovin ${ }^{1}$ \\ The Norwegian Radium Hospi- \\ tal, Oslo, Norway and ${ }^{1}$ Russian \\ Academy of Sciences, Moscow, \\ Russian Federation
}

\begin{abstract}
Immobilized neoglycoconjugates covalently cross-linked into a polyacrylamide gel can be used to detect and characterize carbohydrate-binding proteins. The neoglycoconjugates comprise two active groups, saccharide and allyl, located on a poly(2hydroxyethylacrylamide) backbone. The allyl group cross-links with the polyacrylamide gel matrix, while the saccharide groups are available for specific protein interactions. This neoglycoconjugate gel is prepared as a thin layer within the stacking region of a polyacrylamide gel, and electrophoresis is performed according to native, non-denaturing conditions. Carbohydrate-binding proteins, specific for the immobilized neoglycoconjugates, are thus retarded during electrophoresis, while simultaneously permitting the separation of nonbinding proteins according to size and charge. This new approach can be used to study carbohydrate-binding proteins in the pathology of disease or infection.
\end{abstract}

\section{INTRODUCTION}

A cornerstone of glycobiology research has been the study of carbohydrate-protein interactions. Carbohydrate-binding proteins, generally known as lectins, play a key role in these interactions and have been identified in a diverse range of tissues, cells and organisms. They are known to be involved in many normal and pathological processes, including cell-cell and host-pathogen adhesion mechanisms (22). The complex nature of these interactions, together with the added structural diversity of carbohydrates, has not facilitated rapid progress in this area of glycobiology research.

Neoglycoconjugates, a generic term often used to describe a variety of synthetic carbohydrate-based structures, are powerful tools in many areas of cell biology (11). The well-defined and homogenous nature in which any carbohydrate group(s) can be presented, together with the provision of creating multivalent carbohydrate ligands, is unrivaled by other naturally available substances. Neoglycoconjugates, immobilized to different solid phases, have been used in a variety of applications for the analysis of carbohydrate-protein interactions. Some of these studies have used the inert properties of the acrylamide polymer. A variety of approach- es have been described for the synthesis of sugar-acrylamide copolymers $(4,6,9$, $10,13,24)$, wherein the acrylamide provides an inert backbone for the presentation of the sugar. These principles have been used in affinity chromatography (21) and cell-adhesion assays (19). The method of synthesis described by Bovin $(4,13)$ provides a convenient and reproducible way of preparing well-defined, acrylamide-based neoglycoconjugates. These structures have been used in a variety of approaches including lectin studies (1), immunoassays $(18,23)$ and as immunosorbents in transplantation studies (15). More recently, these neoglycoconjugates have been coated onto paramagnetic particles to facilitate the selection of specific cell populations $(16,17)$.

The trapping of ligands in polyacrylamide or agarose gels has previously been described in affinity-electrophoresis techniques $(7,8)$. The principle is based on the interaction of an immobilized ligand with a migrating macromolecule. Although there are many variants of this approach, the full potential using the new neoglycoconjugate technology has yet to be realized in electrophoretic analyses of carbohydrate-binding proteins.

The method we describe combines the specificity of carbohydrate affinity (CA) interactions with the resolving 
power of gradient polyacrylamide gel electrophoresis (PAGE). Thus it is possible to simultaneously isolate a specific carbohydrate-binding protein while still retaining the traditional electrophoretic separation of nonbinding proteins in a single vertical slab gel. We call this analytical technique CA-PAGE, and it offers a novel approach for the study of carbohydrate-binding proteins.

\section{MATERIALS AND METHODS}

\section{Neoglycoconjugate Polymer Synthesis}

Saccharide-polyacrylamide (PAA) conjugates or neoglycoconjugates (Figure 1A) were prepared by addition of the saccharide, of $>95 \%$ purity as a 3 -aminopropyl glycoside $(4,13)$, in dimethyl formamide (DMF) containing

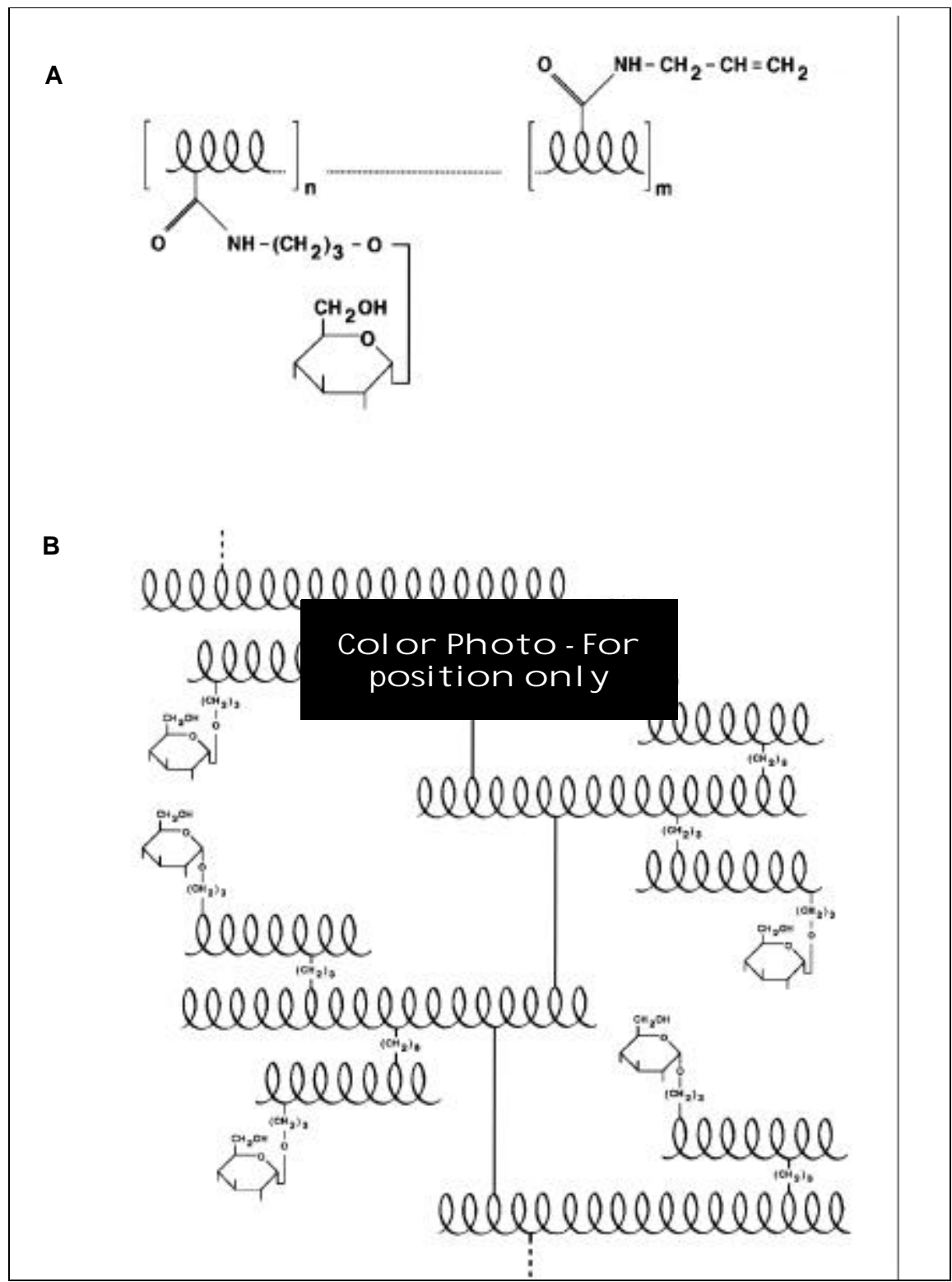

Figure 1. Structure of the neoglycoconjugates used in CA-PAGE. The structure (A) shows the composition of the neoglycoconjugate with a representative saccharide ( $\alpha$-glucose) and the allyl group linked to the acrylamide polymer backbone (blue coil). The presentation of the neoglycoconjugates, when immobilized in the cross-linked (red coil) polyacrylamide affinity gel matrix, is illustrated in Panel B. A single monosaccharide has been shown for simplicity, although a variety of di- and tri-saccharides expressed at different densities can be precisely defined during the synthesis of individual neoglycoconjugates. 
Table 1. Characteristics of the Carbohydrate-Binding Proteins (Lectins) Used

\begin{tabular}{|c|c|c|c|c|}
\hline Source & $\begin{array}{c}\text { Lectin } \\
\text { (common abbrev.) }\end{array}$ & $\begin{array}{c}\text { Nominal } \\
\text { Carbohydrate Specificity }\end{array}$ & Mol Wt & pl \\
\hline Triticum vulgaris & $\begin{array}{l}\text { Wheat germ agglutinin } \\
\text { (WGA) }\end{array}$ & $\begin{array}{c}\beta \text {-N-acetylglucosamine } \\
(\beta G \mid c N A c)\end{array}$ & $\begin{array}{c}36-43 \mathrm{kDa} \\
(18-\mathrm{kDa} \text { subunit) }\end{array}$ & $\mathrm{pH} 9.0$ \\
\hline Canavalia ensiformis & $\begin{array}{c}\text { Concanavalin A or Jack } \\
\text { bean lectin (ConA) }\end{array}$ & $\begin{array}{c}\alpha \text {-Mannose, } \\
\mathrm{N} \text {-acetylglucosamine }\end{array}$ & $\begin{array}{c}106 \mathrm{kDa} \\
\text { (26-kDa subunit) }\end{array}$ & $\mathrm{pH} 5.0$ \\
\hline Galanthus nivalis & $\begin{array}{c}\text { Snowdrop lectin } \\
\text { (GNA) }\end{array}$ & $\alpha$-Mannose & $\begin{array}{c}52 \mathrm{kDa} \\
\text { (13-kDa subunits) }\end{array}$ & $\mathrm{pH} 4.6$ \\
\hline Glycine max & $\begin{array}{l}\text { Soybean lectin } \\
\text { (SBA) }\end{array}$ & $\begin{array}{c}\alpha / \beta-N \text {-acetylgalactosamine } \\
(\alpha / \beta \text { GalNAc })\end{array}$ & $\begin{array}{c}120 \mathrm{kDa} \\
\text { (30-kDa subunit) }\end{array}$ & $\mathrm{pH} 6.0$ \\
\hline Dolichos biflorus & $\begin{array}{l}\text { Horse gram lectin } \\
\text { (DBA) }\end{array}$ & $\begin{array}{c}\alpha-\mathrm{N} \text {-acetylgalactosamine } \\
(\alpha \text { GalNAc })\end{array}$ & $\begin{array}{c}120 \mathrm{kDa} \\
\text { (30-kDa subunit) }\end{array}$ & $\mathrm{pH} 5.5$ \\
\hline Arachis hypogea & $\begin{array}{l}\text { Peanut lectin } \\
\quad \text { (PNA) }\end{array}$ & $\begin{array}{c}\beta \text {-Galactose } \\
\quad(\beta \text {-Gal) }\end{array}$ & $\begin{array}{c}110 \mathrm{kDa} \\
\text { (27-kDa subunit) }\end{array}$ & $\mathrm{nk}$ \\
\hline Ulex europaeus & $\begin{array}{l}\text { Gorse lectin } \\
\quad(\text { UEA-I) }\end{array}$ & $\begin{array}{c}\alpha \text {-Fucose } \\
(\alpha-\text { Fuc })\end{array}$ & $\begin{array}{c}63 \mathrm{kDa} \\
\text { (31-kDa subunit) }\end{array}$ & nk \\
\hline
\end{tabular}

triethylamine, to a solution of poly(4nitrophenylacrylate) and kept at $25^{\circ} \mathrm{C}$ for $16 \mathrm{~h}$. Allylamine was added to the solution and kept at $40^{\circ} \mathrm{C}$ for $24 \mathrm{~h}$. Subsequent concentration of allyl and sugar groups on the neoglycoconjugate was 5 and $20 \mathrm{~mol}$ percent, respectively. Thus 5\% of available amide groups on the PAA were substituted with allyl, while $20 \%$ were substituted with sugar. A further 16-h incubation was carried out in DMF with a 20-fold-50-fold excess of 2-ethanolamine. Purification of the saccharide-PAA-allyl conjugate was then performed using a Sephadex ${ }^{\circledR}$ LH-20 column (Amersham Pharmacia Biotech, Uppsala, Sweden), and the conjugates were eluted with acetonitrile:water (1:1 by vol). SaccharidePAA-allyl conjugate was detected by refractive index. As determined from protein markers by gel filtration, the relative molecular weight $\left(M_{\mathrm{r}}\right)$ of conjugates was approximately $30 \mathrm{kDa}$.

\section{Preparation of Carbohydrate Affinity Gels (CA-PAG)}

All electrophoresis experiments were performed using a Mini-Gel Apparatus (Model SE250; Amersham Pharmacia Biotech, San Francisco, CA, USA). The preparation of single-concentration or gradient-resolving gels comprising a high-pH discontinuous
Tris buffer system ( $\mathrm{pH} 9.5)$ was as described elsewhere (5). The stacking gel however was made in two polymerization steps: the affinity gel layer and then the normal stacking-gel overlay. A stacking-gel solution was prepared comprising $5 \%$ acrylamide, $0.03 \%$ ammonium persulfate in $0.125 \mathrm{M}$ Tris- $\mathrm{HCl}$ buffer ( $\mathrm{pH}$ 6.8) and degassed for 10 $\min$. The affinity gel comprised $0.2 \mathrm{~mL}$ of this solution mixed with up to 213 $\mu \mathrm{g} / \mathrm{mL}$ neoglycoconjugate, together with $0.1 \% \quad N, N, N^{\prime}, N^{\prime}$-tetramethylethylenediamine (TEMED). The solution was immediately added to the gel cassette to form a 5-mm overlay that covers half of the top surface of the resolving gel (Figure 2). After polymerization, the surface of the gel was rinsed and, the remaining acrylamide solution, without neoglycoconjugate, was used to form the second layer of the stacking gel. Sample wells in the second layer of stacking gel were formed using a Teflon ${ }^{\circledR}$ comb in the traditional manner.

\section{Electrophoresis and Western Blotting}

A panel of lectins (Oxford Glycosystems, Oxford, UK) with different carbohydrate-binding specificities (Table 1) were used as test carbohydratebinding proteins. Lectins $(20 \mu \mathrm{g})$ were prepared for electrophoresis in a sam- ple buffer comprising $0.025 \mathrm{M}$ Tris$\mathrm{HCl}$ buffer, $\mathrm{pH}$ 6.8, $0.05 \mathrm{mM} \mathrm{CaCl}_{2}$, $20 \%$ glycerol and trace bromophenol blue. Some lectins are known to require metal ions (usually $\mathrm{Mn}^{2+}$ or $\mathrm{Ca}^{2+}$ ) for their interaction with sugars, and it might be necessary under certain conditions to include these in the sample and/or running buffers. Nonreducing native gel electrophoresis was performed at $4^{\circ} \mathrm{C}$ at $70 \mathrm{~V}$ for 5-6 h. After electrophoresis, the gels were either prepared for Western blotting as described below, or the resolving and stacking gels were fixed and stained in Coomassie ${ }^{\circledR}$ Blue. CA gels and nitrocellulose membranes for Western blotting were pre-soaked in buffer $(0.2 \mathrm{M}$ glycine, $0.25 \mathrm{M}$ Tris- $\mathrm{HCl}$, pH 9.5) containing $0.1 \mathrm{M}$ of the competing free saccharide previously used in the CAgel overlay. Blotting was performed overnight at $4^{\circ} \mathrm{C}$ at a fixed current of 0.3 amps. Transferred lectins were then visualized on nitrocellulose membranes using $0.1 \%$ solution of Amido black in $45 \%$ methanol and $10 \%$ acetic acid for $10 \mathrm{~min}$. The nitrocellulose blots were then destained briefly in 10\% acetic acid until the background was clear.

\section{RESULTS AND DISCUSSION}

We have shown that specific ally- 
lamine-linked neoglycoconjugates can be used in discontinous PAGE for the specific separation of carbohydratebinding proteins. A major advantage of these polyacrylamide-based neoglycoconjugates (3) is the possibility of creating molecules with predetermined properties, combined with low nonspecific protein interaction. The degree of oligosaccharide incorporation, saccharide density or clustering can be chosen simply by altering the proportions of reactants (4). Moreover, unlike previous co-polymerization methods, no free monomer remains in the gel matrix, and the saccharide-PAA-allyl conjugates are far more stable. These neoglycoconjugates, when co-polymerized with acrylamide, form a unique and stable polyacrylamide affinity matrix (Figure 1, A and B). Also, when incorporated as a layer between the resolving and stacking gels (Figure 2), this affinity gel matrix provides a unique separation phase in PAGE. The properties of the polyacrylamide gel, such as the rate of polymerization and stability and handling, are unaffected by concentrations of neoglycoconjugates (up to $250 \mu \mathrm{g}$ ) sufficient to inhibit the migration of $10 \mu \mathrm{g}$ of pure lectin (Figure 3 ). In addition, the Tris-glycine buffer system used in our approach permits the separation of proteins within a wide range of isoelectric points $(\mathrm{pI})$, while still allowing the separation and bind-

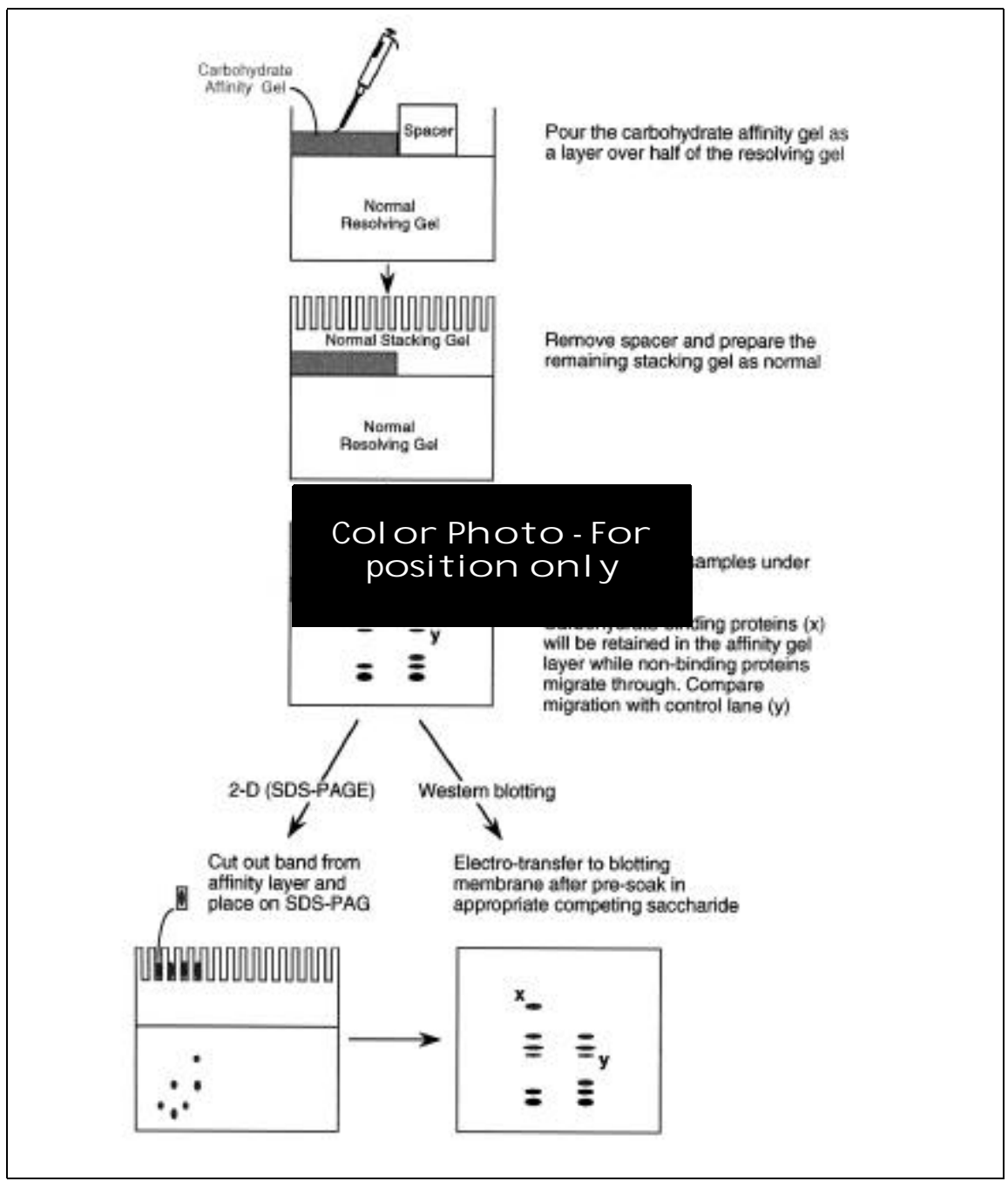

Figure 2. Preparation and orientation of the carbohydrate affinity gel layer in a slab gel electrophoresis format. Carbohydrate-binding proteins (red) are retained by the affinity layer, while nonbinding proteins (black) are separated as normal in the resolving gel. Subsequent analyses can include an SDS-PAGE second dimension and/or Western blotting.

ing of carbohydrate-binding proteins, such as wheat germ agglutinin (WGA) (pI ca. 9.0).

In model experiments using a panel of lectins as carbohydrate-binding proteins (Table 1), the electrophoretic mobility of selected proteins was inhibited by electrophoresis through an affinity gel layer containing immobilized neoglycoconjugates (Figure 3 and 4). The migration of lectins, with no binding specificity for the affinity gel, continued unhindered into the resolving gel. This feature was clearly seen in the electrophoresis of the $\beta$-N-acetylglucosamine ( $\beta$ GlcNAc)-binding lectin WGA through an affinity gel layer containing the $\beta$ GlcNAc neoglycoconjugate (Figure 4A). The remaining lectins (Con A, SBA, PNA, DBA, GNA and UEA) that are not specific for the $\beta$ GlcNAc neoglycoconjugate were unaffected by the affinity gel layer and thus migrated into the native resolving gel. Similarly, only the $\beta-\mathrm{N}$ acetylgalactosamine

( $\beta$ GalNAc)-binding lectin (SBA) was retarded by the $\beta$ GalNAc neoglycoconjugate, while those lectins not specific for this carbohydrate continued to migrate through the resolving gel (Figure 4B). Interestingly, this also shows the specificity of interactions detected by this approach because the $\alpha$ GalNAc-binding lectin (DBA) and the $\beta$-galactose-specific lectin (PNA) were both unaffected by the $\beta$ GalNAc neoglycoconjugate affinity gel layer.

Our approach, in principle similar to affinity chromatography, provides the additional benefit of simultaneous separation of proteins by native gel

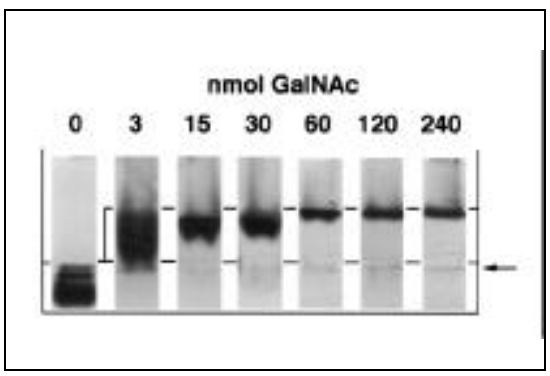

Figure 3. Native CA-PAGE for SBA with different concentrations of the $\beta$ GalNAc neoglycoconjugate. The affinity gel layer comprises 0-240 nmol immobilized GalNAc. Note the non$\beta$ GalNAc-binding contaminant in the SBA preparation (arrow). 
electrophoresis. Analyses can be performed on crude mixtures of proteins, where separation of the carbohydratebinding protein does not affect the resolution or mobility of other nonbinding proteins (Figure 4C). Furthermore, depending on the concentration of neoglycoconjugate, the specific carbohydrate-binding protein can also be retained as a narrow band in a small volume of acrylamide (ca. $4 \mathrm{~mm}^{3}$ ). Subsequent analysis of the isolated native proteins is also possible through the electro-transfer of proteins to a membrane support such as nitrocellulose (Western blotting). The electrotransfer of carbohydrate-binding proteins from the affinity gel matrix is illustrated for the $\beta$ GlcNAc-binding lectin (WGA), which was blotted in transfer buffer containing $0.1 \mathrm{M}$ GlcNAc (Figure 5). This simple transfer of carbohydrate-binding proteins from the affinity gel matrix permits further analyses such as immunostaining or sequencing. Although the Tris-glycine buffer system is not the buffer of choice for subsequent sequence analysis, extensive washing of transfer membranes is often regarded as a sufficent pretreatment.

The CA-PAGE technique, in a single slab gel, separates proteins on the basis of functional characteristics in addition to the more traditional size and charge criteria of a native gel electrophoresis fractionation. However, the technique can also be incorporated into

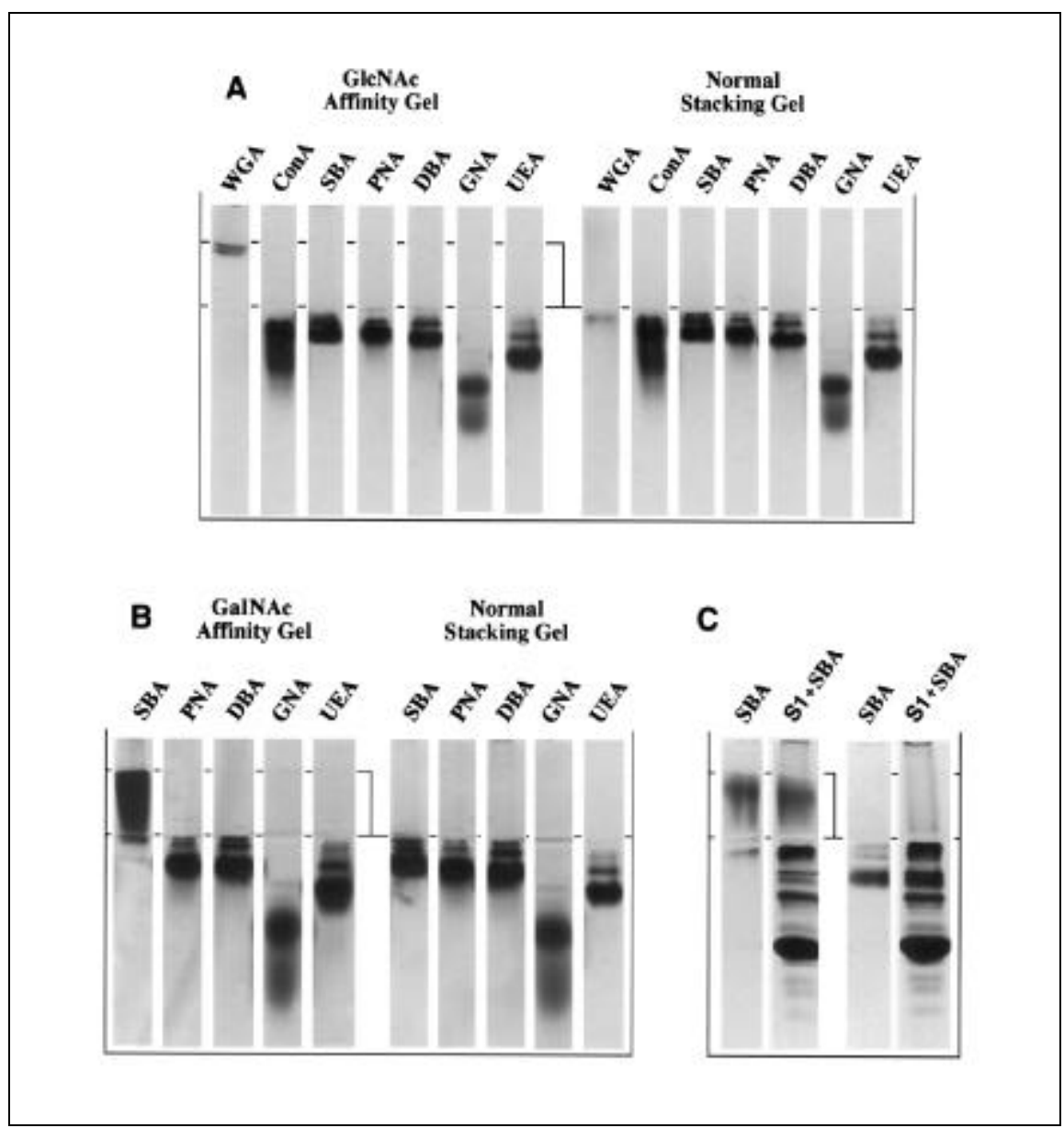

Figure 4. Native CA-PAGE of selected lectins with different affinity gels. Note the retarded migration of WGA in the affinity gel layer containing immobilized $\beta$ GlcNAc (A) and SBA in the affinity gel layer containing immobilized $\beta$ GalNAc (B). Control lanes are shown with normal stacking gels. Lectins not specific for these saccharides migrate through the affinity gel matrix. Native CA-PAGE of normal serum (S1) with and without SBA (C) shows that the migration of nonbinding proteins is unaffected by SBA bound in the affinity matrix. Similarly, the binding of the SBA appears to be unaffected in the presence of a complex mixture of nonbinding proteins.

a two-dimensional analysis (Figure 2). The region of the affinity gel containing the carbohydrate-binding protein(s) can be cut out $(6 \times 2-\mathrm{mm}$ slice $)$ and placed in a stacking well of a denaturing sodium dodecyl sulfate (SDS) polyacrylamide gel. The subsequent electrophoresis provides additional information regarding the subunit structure of the carbohydrate-binding protein. One significant advantage is the ability to compare multiple samples in the same second-dimension gel.

There are many areas in both clinical and basic research where the CAPAGE approach could be used. Prion proteins are thought to bind sulfated glycans in brain tissues (20) and these interactions could be studied using CAPAGE. Lectins with identical binding properties, as recently documented in the Galectin family of $\beta$-galactosidebinding proteins (12), could be resolved using CA-PAGE as the first dimension. CA-PAGE also provides a rapid approach in screening serum samples, cells or tissues for new carbo-

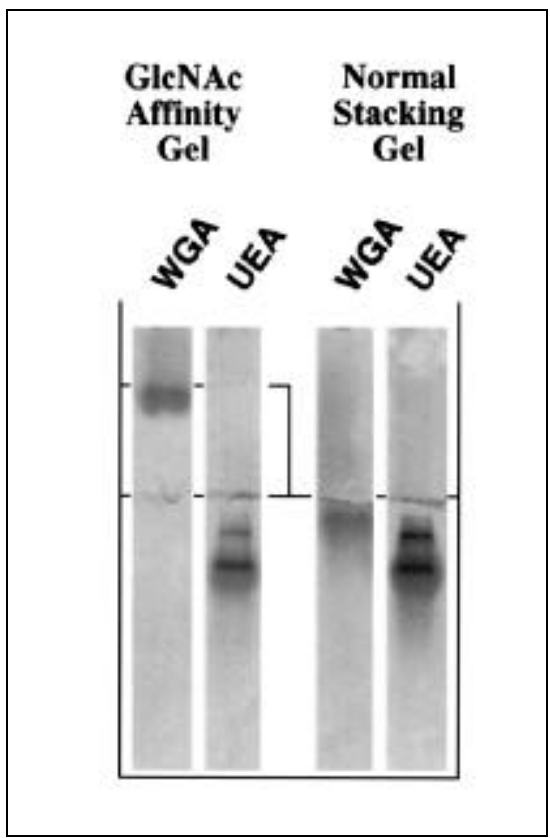

Figure 5. Western blot of WGA and UEA from an affinity gel containing the saccharide BGIcNAc. After CA-PAGE electrophoresis of WGA and a control non- $\beta$ GlcNAc-binding lectin (UEA), the gel was transferred to a nitrocellulose membrane by electro-blotting. Amido black staining of the membrane illustrates the successful transfer of both the UEA control and the WGA from the affinity gel matrix. 
hydrate-binding proteins that can have prognostic or diagnostic value. The principles of CA-PAGE can also be applied in the study of carbohydrate-carbohydrate interactions between oligosaccharide chains on mucins. This type of interaction has been proposed as the basis of specific cell adhesion and autoaggregation mechanisms and, more recently, for the packing of $\mathrm{Le}^{\mathrm{x}} / \mathrm{Le}^{\mathrm{x}}$ carbohydrate blood group structures, which may be compatible with cell-cell recognition $(2,14)$.

Thus, CA-PAGE provides a new angle of approach in a rapidly developing area of glycobiology, by combining the principles of neoglycoconjugate chemistry and traditional electrophoresis. We have shown that these technologies can be further exploited through CAPAGE for unraveling the diverse and complex interactions of carbohydrates and their binding proteins.

\section{ACKNOWLEDGMENTS}

This research was supported by a grant from the Norwegian Research Council. We are grateful to Dr. A. Tuzikov for the synthesis of neoglycoconjugates. The authors would also like to acknowledge the support and encouragement of Dr. E. Hovig and Prof. $\emptyset y$ stein Fodstad, at the Norwegian Radium Hospital.

\section{REFERENCES}

1.Adler, P., S.J. Wood, Y.C. Lee, R.T. Lee, W.A. Petri and R.L. Schnaar. 1995. High affinity binding of the Entamoeba histolytica lectin to polyvalent $\mathrm{N}$-acetylgalactosamides. J. Biol. Chem. 270:5164-5174

2.Bovin, N.V. 1997. Carbohydrate-carbohydrate interaction, p. 277-289. In H.-J. Gabius and S. Gabius (Eds.), Glycosciences: Status and Perspectives. Chapman \& Hall, London.

3.Bovin, N.V. 1996. Polyacrylamide-based glycoconjugates as tools for studying lectins, antibodies, and glycosyltransferases in glycobiology, cytochemistry, and histochemistry. Russ. J. Bioorgan. Chem. 22:547-566.

4.Bovin, N.V., E. Yu Korchagina, T.V. Zemlyanukhina, N.E. Byramova, O.E. Galanina, A.E. Zemlyakov, A.E. Ivanov, V.P. Zubov and L.V. Mochalova. 1993. Synthesis of polymeric neoglycoconjugates based on $\mathrm{N}$ substituted polyacrylamide. Glycoconj. J. 10:142-151.

5.Davis, B.J. 1964. Disc electrophoresis - II. Method and application to human serum proteins. Ann. NY Acad. Sci. 121:404-427.
6.Fukase, K., H. Nakayama, M. Kurosawa, T. Ikegaki, T. Kanoh, S. Hase and S. Kusumoto. 1994. Functional fluorescence labeling of carbohydrates and its use for preparation of neoglycoconjugates. J. Carb. Chem. 13:715736.

7.Heegaard, N.H.H. and O.J. Bjerrum. 1991. Affinity electrophoresis used for determination of binding constants for antibody-antigen reactions. Anal. Biochem. 195:319-326.

8.Horejsi, V. 1984. Affinity Electrophoresis. Methods Enzymol. 104:275-281.

9.Lee, R.T., S. Cascio and Y.C. Lee. 1979. A simple method for the preparation of polyacrylamide gels containing thioglygoside ligands. Anal. Biochem. 95:260-269.

10.Lee, R.T. and Y.C. Lee. 1982. Preparation of polyacrylamide gels containing thioglycoside. Methods Enzymol. 83:299-305.

11.Lee, Y.C. and R.T. Lee. 1994. Neoglycoconjugates: Preparation and Applications. Academic Press, San Diego.

12.Lutomski, D., M. Caron, J-D. Cornillot, P. Bourin, C. Dupuy, M. Pontet, D. Bladier and R. Joubert-Caron. 1996. Identification of different galectins by immunoblotting after two-dimensional polyacrylamide gel electrophoresis with immobilized $\mathrm{pH}$ gradients. Electrophoresis 17:600-606.

13.Nifant'ev, N.E., A.S. Shashkov, Y.E Tsvetkov, A.B. Tuzikov, I.V. Abramenko, D.F. Gluzman and N.V. Bovin. 1994. Synthetic probe for the study of molecules related to selectin family, p. 267-275. In P. Kovac (Ed.), Synthetic Oligosaccharides: Indispensable Probes for the Life Sciences. ACS Symp. Ser. American Chemical Society: Washington DC.

14.Pérez, S., N. Mouhous-Riou, N.E. Nifant'ev, Y.E. Tsvetkov, B. Bachet and A. Imberty. 1996. Crystal and molecular structure of a histo-blood group antigen involved in cell adhesion: the Lewis $\mathrm{x}$ trisaccharide. Glycobiology 6:537-542.

15.Rieben, R., E.Y. Korchagina, E. von Allmen, J. Kremer-Hovinga, B. Lammle, T.W. Jungi, N.V. Bovin and U.E. Nydegger. 1995. In vitro evaluation on the efficacy and biocompatibility of new, synthetic ABO immuno-absorbents. Transplantation 60:425430.

16.Rye, P.D. 1996. Sweet and sticky: carbohydrate-coated magnetic beads. Bio/Technology 14:155-157.

17.Rye, P.D. and N.V. Bovin. 1997. Selection of carbohydrate-binding cell phenotypes using oligosaccharide-coated magnetic particles. Glycobiology 7:179-182.

18.Rye, P.D., N.V. Bovin, E.V. Vlasova and R.A. Walker. 1995. Monoclonal antibody LU-BCRU-G7 against a breast tumor-associated glycoprotein recognizes the disaccharide Galß1-3GlcNAc. Glycobiology 5:385-389.

19.Schnaar, R. 1994. Immobilized glycoconjugates for cell recognition studies, p. 423-425. In Y.C. Lee and R.T. Lee (Eds.), Neoglycoconjugates: Preparation and Applications. Academic Press, San Diego.

20.Shyng, S.L., S. Lehman, K.L. Moulder and D.A. Harris. 1995. Sulfated glycans stimulate endocytosis of the cellular isoform of the prion protein, $\mathrm{PrP}^{\mathrm{c}}$, in cultured cells. J. Biol.
Chem. 270:30221-30229.

21.Sutoh, K., S. Rosenfeld and Y.C. Lee. 1977. Isolation of peanut lectin by affinity chromatography on polyacrylamide-entrapped guar beads and polyacrylamide (co-allyl alpha-D-galactopyranoside). Anal. Biochem. 79:329-337.

22.Varki, A. 1993. Biological roles of oligosaccharides: all of the theories are correct. Glycobiology 3:97-130.

23.Vlasova, E.V., N.E. Byramova, A.B. Tuzikov, L.S. Zhigis, E.M. Rapoport, S.V. Khaidukov and N.V. Bovin. 1994. Monoclonal antibodies directed to the synthetic carbohydrate antigen Ley. Hybridoma 13:295301.

24.Wiegel, P.H., R.L. Schnaar, S. Roseman and Y.C. Lee. 1982. Preparation of polyacrylamide gels containing copolymerized $\omega$-acrylamidoalkyl glycosides. Methods Enzymol. 83:294-299.

Received 13 November 1997; accepted 2 February 1998.

Address correspondence to:

Dr. Phil D. Rye

Department of Tumor Biology

Institute for Cancer Research

The Norwegian Radium Hospital

Montebello 0310

Oslo, Norway

Internet:prye@radium.uio.no 